УДК 658.562

DOI 10.30679/2219-5335-2020-2-62-84-99

КОМПЕТЕНТНОСТЬ

ИСПЫТАТЕЛЬНЫХ ЛАБОРАТОРИЙ ГАРАНТИЯ ЭФФЕКТИВНОГО

КОНТРОЛЯ КАЧЕСТВА И БЕЗОПАСНОСТИ ПРОДУКЦИИ

Шелудько Ольга Николаевна д-р техн. наук, доцент ведущий научный сотрудник зав. НЦ «Виноделие»

e-mail: scheludcko.olga@yandex.ru

Федеральное государственное бюджетное научное учреждение «Северо-Кавказский федеральный научный центр садоводства, виноградарства, виноделия», Краснодар, Россия

Стрижов Николай Константинович д-р хим. наук, профессор e-mail: nikolai.strizhov@yandex.ru

Хевсокова Маргарита Валерьевна 3 курс магистратуры e-mail: margo22011996@mail.ru

Игнатенко Ольга Юрьевна

3 курс магистратуры

e-mail: olga_ignatenko_1994@mail.ru

Шнаревич Алина Максимовна

3 курс магистратуры

e-mail: alinashnarevich@mail.ru

Кубанский государственный технологический университет, Краснодар, Россия

Контроль качества и безопасности продукции напрямую зависит от компетентности испытательной лаборатории. В связи с совершенствованием нормативно-правовой базы по вопросам качества и пищевой безопасности растут требования и к испытательным
UDC 658.562

DOI 10.30679/2219-5335-2020-2-62-84-99
COMPETENCE OF TESTING

LABORATORIES WARRANTY OF EFFECTIVE QUALITY CONTROL AND PRODUCT SAFETY

Shelud'ko Olga Nikolaevna Dr. Tech. Sci., Docent Leading Research Associate Head of CS «Wine-making» e-mail: scheludcko.olga@yandex.ru

Federal State Budget

Scientific Institution «North Caucasian Federal Scientific

Center of Horticulture, Viticulture, Wine-making», Krasnodar, Russia

Strizhov Nikolay Konstantinovich Dr. Sci. Chemic., Professor e-mail: nikolai.strizhov@yandex.ru

Khevsokova Margarita Valerevna 3 magistracy course e-mail: margo22011996@mail.ru

Ignatenko Olga Yuryevna

3 magistracy course e-mail: olga_ignatenko_1994@mail.ru

Shnarevich Alina Maksimovna 3 magistracy course e-mail: alinashnarevich@mail.ru

\section{Kuban State}

Technological University, Krasnodar, Russia

Quality control and product safety directly depends on the competence of the testing laboratory. In connection with the improvement of the regulatory framework on quality and food safety increase in requirements for testing laboratories. The relevance of the article 
лабораториям. Актуальность статьи связана с внедрением новой версии действующего международного стандарта ISO/IEC 17025 «Общие требования к компетентности испытательных и калибровочных лабораторий». В статье проведён анализ ключевых изменений документа и даны рекомендации для их внедрения в деятельность испытательных лабораторий. Определена роль требований науки, законодательства и заказчика. Показано, что переход испытательных лабораторий на новую версию стандарта позволит доказать, что они действуют профессионально и способны давать технически обоснованные результаты. Описаны элементы риск-ориентированного подхода, вводящие требования, основанные на производственной функциональности. Предложено разработать алгоритм менеджмента рисков. Отмечено, что новым документом в отношении требований к процессам, процедурам, документированной информации и организационных обязанностей предусмотрена большая гибкость, чем в предыдущей версии. Определена область применения стандарта лабораторная деятельность, описан круг работ для лаборатории, сделан акцент на постоянном анализе профессионализма персонала. Рассмотрены актуальные вопросы информационных технологий, определена значимость применения в лабораторной деятельности специализированных компьютерных программ, позволяющих выполнять сложные статистические расчёты, ведение контрольных карт и т.д. Уточнена метрологическая прослеживаемость и ответственность за ее обеспечение в лаборатории. Описаны правила принятия решений для заявлений о соответствии. Показано, что новые изменения

в лабораторной деятельности повысят надежность результатов испытаний и увеличат эффективность контроля качества и безопасности продукции, is connected with the introduction of a new version of the current international standard ISO / IEC 17025 «General requirements for the competence of testing and calibration laboratories»». The article analyzes the key changes of the document and the recommendations for their implementation in the activities of testing laboratories are given.

The role of the requirements of science, legislation and the customer is defined.

It is shown that the transition of testing Laboratories to the new standard version will allow to prove that they are acting professionally and capable to give the technically sound results. Elements of a risk-based approach are described, as well as the introducing requirements, based on production functionality.

Suggested to develop the algorithm of risk management. Noted that new document regarding the requirements or processes, procedures, documented information and organizational responsibilities is more flexibility than that in the previous version. The area of the standard laboratory activity is defined, the set of work for the laboratory is described, accent on a constant analysis of the professionalism of laboratory personnel is made. Aspects of competency confirmation for employees are described. The relevant issues of information technology are observed, the importance of using the specialized computer programs in the laboratory is defined that allow to carry out the complex statistical calculations and keeping of control charts. The responsibility for metrological traceability and its provision in the laboratory is specified. The rules of decision adoption for declarations about conformity are described. It is shown that new changes in laboratory activities will increase in the reliability of test results, and the effectiveness of quality control, 
Плодоводство и виноградарство Юга России № 62(2), 2020 г.

обеспечат её высокую конкурентоспособность.

Ключевые слова: КОНТРОЛЬ КАЧЕСТВА ПРОДУКЦИИ, ИСПЫТАТЕЛЬНАЯ ЛАБОРАТОРИЯ, ТРЕБОВАНИЯ, ДОСТОВЕРНОСТЬ РЕЗУЛЬТАТОВ and product safety and the high product competitiveness will provide.

Key words: CONTROL OF PRODUCT QUALITY, TEST LABORATORY, REQUIREMENTS, RESPONSIBILITY OF RESULTS

Введение. Улучшение качества продукции и гарантия ее безопасности являются важнейшими направлениями интенсивного развития экономики, источником экономического роста и эффективности производства [1-3]. Стремительное формирование технического законодательства как совокупности правовых норм, регламентирующих требования к техническим объектам, в том числе к продукции и процессам ее жизненного цикла, продиктовано обеспечением роста развития экономики России темпами выше среднемировых и конечной целью - повышение качества жизни.

Федеральный закон от 27.12.2002 № 184-Ф3 «О техническом регулировании» определяет его главные элементы: разработку, принятие и исполнение обязательных требований к продукции, процессам жизненного цикла продукции (далее - ЖЦП); установление и применение на добровольной основе требований к продукции, процессам ЖЦП; выполнению работ или оказанию услуг; оценку соответствия. Первый элемент реализуют через принятие и применение технических регламентов на продукцию и правила метрологии; второй - через стандарты и третий - через оценку соответствия, включающую испытание продукции на соответствие установленным нормируемым показателям качества и безопасности.

В настоящее время, в условиях рыночной экономики, большое внимание уделяется конкурентоспособности продукции как на внутреннем, так и на мировых рынках [3-5]. Основой решения поставленных задач является не только повышение уровня качества и потребительской безопасности продукции, но и качественное проведение процедуры подтверждения соответствия [6-8]. 
Плодоводство и виноградарство Юга России № 62(2), 2020 г.

Заключение о соответствии продукции установленным требованиям основывается на протоколах испытательных лабораторий, профессионализм которых напрямую влияет на обоснованность и достоверность результатов проведённых испытаний, а значит, и на качество продукции, выходящей на рынок.

Выводу российской продукции на экспорт могут способствовать только высококомпетентные лаборатории, способные доказать своё соответствие трём ключевым принципам: независимости, беспристрастности и компетентности с помощью аккредитации.

Критерии аккредитации, включающие основные направления формирования системы менеджмента аккредитованной испытательной лаборатории, определены приказом Минэкономразвития России от 30 мая 2014 г. № 326 «Об утверждении критериев аккредитации, перечня документов, подтверждающих соответствие заявителя, аккредитованного лица критериям аккредитации, и перечня документов в области в области стандартизации, соблюдение требований которых заявителями, аккредитованными лицами обеспечивает их соответствие критериям аккредитации» [9-10].

Согласно приказу Росстандарта от 15 июля 2019 г. № 385-ст с 1 сентября 2019 г. вводится в действие в качестве национального стандарта Российской Федерации ГОСТ ISO/IEC 17025-2019 «Общие требования к компетентности испытательных и калибровочных лабораторий», идентичный международному стандарту ISO/IEC 17025:2017 (далее - ISO/IEC 17025) [11].

Переход испытательной лаборатории как участника национальной системы аккредитации на новую версию стандарта основывается на зарубежном опыте практической реализации требований стандарта, предусматривает участие в информационных кампаниях, организацию обучения ключевого персонала с последующим внесением изменений в систему менеджмента лаборатории, проведение внутреннего аудита и самообследования [11-14]. 
Обсуждение. Как показал международный опыт с 1997 г. по 2018 г. лаборатории, применяющие текущие версии стандарта ISO/IEC 17025 дают более качественный результат, большую стабильность и меньшую погрешность. Новая версия стандарта ISO/IEC 17025 ставит на первое место требования науки, законодательства и лишь на третье - удовлетворение требований заказчика. Стандарт содержит требования для испытательных лабораторий, позволяющие им доказать, что они действуют профессионально и способны давать технически обоснованные результаты - это стандарт обеспечения и контроля качества, который применим ко всем организациям, занимающимся лабораторной деятельностью, независимо от численности персонала.

В соответствии с приказом Росаккредитации от 9 августа 2019 года № 144 в испытательной лаборатории должен быть составлен план гармоничного перехода на применение ISO/IEC 17025 и мероприятий обеспечения корректировки действующей системы менеджмента. Особенностью переходного периода на новую версию стандарта [11-14] для испытательной лаборатории должно стать повышение требований к получаемым результатам испытаний, что влечёт за собой целый спектр важных изменений и доработок.

К основным ключевым изменениям документа относится рискориентированный подход. Новая версия стандарта вносит требования к лабораториям в планировании и осуществлении действий по оценке рисков и возможностей, что позволит уменьшить число требований, предписывающих действия, и замену их требованиями, ориентированными на результат [11]. Предполагается, что лаборатория планирует и осуществляет действия по оценке рисков и возможностей. Поэтому целесообразна разработка алгоритма менеджмента рисков, включающего выявление возможных рисков, их оценку (переоценку) и ранжирование, минимизацию рисков наивысшего ранга, оценку результативности реализованных 
Плодоводство и виноградарство Юга России № 62(2), 2020 г.

мероприятий с выявлением новых рисков и далее по замкнутому циклу с документированием результатов анализа рисков.

В новой версии стандарта ISO/IEC 17025 сделан акцент на «беспристрастность» против «независимости». Новые требования определяют идентифицирование рисков беспристрастности на постоянной основе и их устранение. В соответствии с п. 4.1 лаборатория должна чётко определиться с идентификацией возможных рисков в процессе своей деятельности, исключить давление, которое может угрожать беспристрастности при проведении испытаний и получении достоверных результатов. Принятые испытательной лабораторией обязательства по беспристрастности должны быть оформлены документом внутреннего пользования [11].

Установлены новые требования к конфиденциальности касательно повышенного внимания к осведомлённости заказчика. Представлена более подробная информация о конкретных случаях, когда может быть затронута конфиденциальность. Новые требования предполагают, что заказчик должен быть заранее проинформирован, если лаборатория планирует разместить те или иные данные в открытых источниках, поэтому их необходимо включать в контракт (договор).

Пересмотрены требования к ресурсам: лаборатория должна располагать персоналом, помещениями, оборудованием, системами и вспомогательными службами, необходимыми для управления лабораторной деятельностью и для ее осуществления. Термин «располагать» указывает на подход в пересмотре, который фокусируется не столько на владении ресурсами, сколько на соответствующих требованиях к этим ресурсам.

Обеспечение качества проводимых испытаний возможно только компетентным персоналом. Требования к персоналу определены в п.6.2 [11]. Весь персонал должен действовать беспристрастно, быть компетентным и проводить работы в соответствии с системой менеджмента лаборатории. Персонал должен быть уполномочен на выполнение следующих задач: 
Плодоводство и виноградарство Юга России № 62(2), 2020 г.

- $\quad$ анализ результатов испытаний с целью оценки достоверности и правильного представления;

- $\quad$ подготовку отчётов о результатах, их проверку и утверждение;

- отработку, верификацию и валидацию методов $[11,15]$.

В плане лаборатории переходного периода есть ряд мероприятий, направленных на проверку деятельности и компетентности сотрудников лаборатории и обучение требованиям нового стандарта.

Проверка компетентности персонала должна быть основана на усовершенствованной системе аттестации. Аттестация может проводиться с помощью различных методов:

- наблюдение за работой сотрудников: этот метод является трудоёмким, но он позволяет наиболее точно выявить все недостатки в уровне подготовки персонала лаборатории;

- $\quad$ мониторинг и проверка документации: аттестация проводится на основе записей, документации и данных;

- выполнение аттестационных заданий: для каждой должности необходимо составить и утвердить специальные задания как теоретического, так и практического характера; проверка компетенций сотрудников выполняется на основе анализа результатов этих заданий;

- сравнительная оценка: проводится сравнение работы сотрудников между собой, в целях аттестации сотрудники должны выполнять один и тот же вид работ.

Результаты проведённой аттестации оформляют документально. Требования к персоналу лаборатории, включающие требования к образованию, опыту, уровню знаний, составу задач, ответственности и правам каждой должности, должны быть представлены в должностных инструкциях.

Стандарты, справочные материалы, реактивы, эталоны, расходные материалы, вспомогательное оборудование, измерительные инструменты и программное обеспечение отнесены к понятию оборудование [11]. Приведены условия, при которых следует калибровать (поверять) оборудование: 
Плодоводство и виноградарство Юга России № 62(2), 2020 г.

- $\quad$ если точность или неопределённость измерений влияют на достоверность полученных результатов;

- если необходима калибровка для установления метрологической прослеживаемости полученных результатов.

Предложено адаптировать и расширить систему управления оборудованием в отношении стандартов, справочных материалов, реактивов, эталонов, расходных материалов, вспомогательного оборудования, измерительных инструментов и программного обеспечения. Предусмотрено вести записи, в которых указывают условия хранения, калибровка (если возможно), записи о ремонте, неисправностях.

Метрологическая прослеживаемость рассматривается в отдельном пункте стандарта. Дополнительная пояснительная информация включена в Приложение A, показывающая возможности для установления и демонстрации прослеживаемости. Для установления метрологической прослеживаемости обозначена важность правильного представления результатов измерений [15-17].

Правильность выполнения измерений и компетентность персонала испытательной лаборатории наглядно характеризует значение погрешности результатов. Методиками выполнения измерений могут быть только методы, включенные в область аккредитации лаборатории. Внутренние проверки и межлабораторные сличения должны подтверждаться соответствующими протоколами.

Испытательная лаборатория должна документировать:

- использование стандартных растворов и образцов (поступление, условия хранения, сроки хранения, расход и даты применения); стандартные образцы должны быть прослеживаемыми к единицам СИ и к стандартным образцам утверждённого типа $[11,18]$;

- оценивание неопределённости измерений на каждом этапе применения согласованных методов [11, 16, 17]; 
Плодоводство и виноградарство Юга России № 62(2), 2020 г.

- $\quad$ реализацию каждого этапа в цепи прослеживаемости с применением соответствующих методов, с получением результатов измерений и связанных с ними зарегистрированных значений неопределённости измерений.

В качестве основы для сравнения могут выступать: единица измерения, методика измерений, эталон (в том числе государственный стандартный образец) или их сочетание. Ответственность за обеспечение метрологической прослеживаемости возложена на испытательную лабораторию. Чтобы отразить последние изменения в рыночных отношениях, авторы новой редакции стандарта расширили требования п. 7.1, предъявляемые к лаборатории при работе с поставщиками, подрядными организациями.

В отличие от версии 2009 года теперь для привлечения субподряда в лабораторную деятельность необходимо согласие заказчика. Ориентир на общение с заказчиком - привлечение субподряда в случае, когда лаборатория не располагает ресурсами или компетентностью для выполнения работ либо по техническим причинам не может осуществить их полностью или частично [11].

В п. 7.2 включены выбор, верификация и валидация методов. Новые понятия «верификация и валидация методики» являются деятельностью для получения подтверждения того, что лаборатория обладает необходимыми характеристиками $[11,15]$. «Когда требуется разработка методики, это подразумевает запланированную деятельность, осуществляемую компетентным персоналом с предоставлением соответствующих ресурсов. По мере развития методики проводится периодический анализ, подтверждающий, что потребности заказчика выполняются на должном уровне. Любые изменения в плане разработки утверждают и одобряют в установленном порядке» [11]. Эти изменения обязывают лабораторию при использовании стандартизованных методов документировать верификацию методик. 
Отбор образцов (проб) теперь осуществляется как лабораторная деятельность, в связи с чем лаборатории следует адаптировать процедуры оценки неопределённости измерений для включения компонента отбора образцов при необходимости.

Для усовершенствования работ по обеспечению качества результатов испытаний и калибровки в новой версии стандарта расширены процедуры анализа и планирования результатов (п. 7.7). Обеспечение достоверности результатов разделяет два требования к достоверности результатов деятельности: путём мониторинга внутри лаборатории и между лабораториями. Качество внутрилабораторного контроля рассматривается как основной фактор, подтверждающий способность лаборатории выполнять исследования на должном уровне, определяемом достоверностью, точностью, правильностью, прецизионностью в условиях повторяемости и внутрилабораторной воспроизводимости результатов [19-21].

В новой версии стандарта присутствуют дополнительные инструменты контроля качества, например в целях прослеживаемости результатов использование альтернативного поверенного оборудования. Лаборатория обязана участвовать в проверках квалификации и (или) межлабораторных сличениях, отличных от проверок квалификации. Оба требования планируют, проверяют, анализируют и используют для контроля и улучшения лабораторной деятельности, а также для оперативного реагирования на возникновение несоответствий, установления причины и принятия срочных мер для их устранения.

В п. 7.8 предоставление отчётов о результатах к новым требованиям стандарта относится представление заключений о соответствии, по которым лаборатория должна документировать правило принятия решения (учёт неопределённости измерений при принятии решения о соответствии). Лаборатория несёт всю ответственность за информацию в отчёте, кроме информации, предоставленной заказчиком, которая должна быть чётко идентифицирована [11]. 
Стандарт предъявляет более широкий круг требований к процессу обращения с жалобами (претензиями). Необходимо, чтобы описание процедуры обращения с жалобами (претензиями) было доступно всем заинтересованным сторонам по запросу, результаты рассмотрения жалобы (претензии) должны быть приняты или рассмотрены и одобрены лицами, которые не принимали участия в лабораторной деятельности, то есть соблюдено требование к беспристрастности.

В отличие от версии 2009 года обновлённая версия стандарта уделяет больше внимания информационным технологиям, учитывая современные требования, и включает использование компьютерных систем, ведение записей на электронных носителях и выпуск результатов и отчётов в электронном виде. Вся глава полностью была изменена и адаптирована для обработки данных электронной информации.

Лаборатория может иметь систему управления информацией, применимую к электронной и обычной информации. Требования к системам управления информацией лаборатории не должны ограничиваться только компьютеризованными системами (Laboratory Information Management System), а включать также любой тип системы по обработке данных $[11,22]$. Основными их видами являются специализированные компьютерные программы, которых в лаборатории может быть несколько, и каждая из них ориентирована на определённый вид деятельности.

В России шире всего распространены специализированные программы QualityControl с блоком SampleControl и DocumentControl [23]. Специализированная программа позволяет лабораториям использовать современные подходы, включающие сложные статистические расчёты, ведение контрольных карт и т.д. По результатам измерений программа рассчитывает результаты анализа, выполняет контроль стабильности измерений, а также валидацию и верификацию методик. 
Например, QualityControl разработана для компьютеризации работы лаборанта, включая расчёт результатов измерений (с использованием градуировочных характеристик и формул), проверку их приемлемости, контроль стабильности по контрольным картам и другие способы контроля. Программа содержит лабораторный журнал. При его использовании лаборант только выполняет измерения - все остальное делает программа. Блок SampleControl позволяет регистрировать поступившие в лабораторию образцы и партии образцов, следить за их движением по лаборатории, генерировать протоколы, вести статистику исследований за любой период времени и т.д.

Программа DocumentControl предназначена для компьютеризации остальных видов деятельности лаборатории. Она позволяет вести все необходимые виды учёта - учёт документов, реактивов, материалов, стандартных образцов, оборудования (в том числе средств измерений), сотрудников (отдел кадров), умеет регистрировать претензии, проводить внутренние проверки и корректирующие действия.

Обязательным условием стала проверка систем на наличие целостности, несанкционированного доступа, защиты от несанкционированного доступа. Система должна поддерживаться надлежащим образом и храниться в подходящей среде.

Добавленная глава 8, требования к системе менеджмента, является новой и предлагает 2 варианта [11]. Вариант А определяет минимальные требования для системы менеджмента. В варианте В указано, что минимальные требования считаются выполненными, если лаборатория соответствует стандарту системы ISO 9001, а также отвечает требованиям статей 4-7.

Первое, что необходимо выполнить руководству лаборатории, это провести самооценку действующей системы менеджмента.

На основании полученных данных оформить анкету самообследования на соответствие требованиям ISO/IEC 17025. Необходимо оценить 
Плодоводство и виноградарство Юга России № 62(2), 2020 г.

и внести изменения в документацию системы менеджмента в целях соответствия новому стандарту.

Актуализация документации системы менеджмента является основанием для проведения внутреннего аудита по реализации обновленных требований. Изменение системы менеджмента лаборатории позволит поддерживать систему менеджмента соответствующей стандарту ISO 9001 [24].

Добавленная глава заменяет собой концепцию профилактических действий. Лаборатория должна принимать во внимание риски и возможности, связанные с лабораторной деятельностью, для того чтобы гарантировать, что система управления достигнет запланированных результатов.

Согласно новой редакции для лабораторий отсутствует необходимость проведения внутренних аудитов ежегодно. Актуальность проведения мероприятий, изменений в лаборатории и результатов предыдущих проверок должна учитываться в программе каждого аудита. По этим причинам при планировании аудита рекомендовано учитывать значимость проверяемых видов деятельности в рамках конкретного контекста лаборатории, итоги предыдущих внутренних и внешних аудитов и т. п.

Bbыводы. Таким образом, проведённый анализ показал, что новая версия стандарта ISO/IEC 17025 предусматривает большую гибкость в отношении требований к процессам, процедурам, документированной информации и организационным обязанностям по сравнению с предыдущей. Стандарт предъявляет требования к структуре, ресурсам и оборудованию лаборатории, описывает процессы испытаний или калибровки и поддержки системы менеджмента качества. Пересмотр стандарта ISO/IEC 170252019 учитывает деятельность и новые способы функционирования лабораторий на сегодняшний день, а также обладает опережающей функцией.

Переход испытательных лабораторий на новую версию стандарта будет способствовать улучшению СМК, повышению эффективности, ста- 
Плодоводство и виноградарство Юга России № 62(2), 2020 г.

бильности, позволит дать гарантии заинтересованным сторонам вследствие увеличения уровня доверия к деятельности лабораторий. Новые изменения повысят надёжность результатов испытаний, увеличат эффективность контроля качества и безопасности продукции и обеспечат её высокую конкурентоспособность.

\section{Литература}

1. Хуршудян С.А. Потребитель и качество пищевых продуктов // Пищевая промышленность. 2014. № 5. С. 16-18.

2. Lapidus V.A., Kastorskaya L.V., Serov M.E., Voinova E.G. Principles and approaches to management in system of quality guarantee // Methods of Quality Management. 2018. № 7. P. 46-52.

3. Шелудько О.Н., Стрижов Н.К., Гугучкина Т.И., Гузик Т.В. Графический образ высококачественных вин // Аналитика и контроль. 2018. Т. 22. № 3. С. 315-326.

4. Шелудько О.Н., Стрижов Н.К. Применение комплексного анализа при оценке качества винодельческой продукции // Известия высших учебных заведений. Пищевая технология. 2018. № 5-6 (365-366). С. 116-120.

5. Марковский М.Г., Бурцев Б.В., Гугучкина Т.И., Шелудько О.Н. Исследование распределения и взаимосвязи макро- и микроэлементов в винах в целях определения возможности их географической идентификации [Электронный ресурс] // Плодоводство и виноградарство Юга России. 2019. № 59(5). С. 155-166. URL: http://journalkubansad.ru/pdf/19/05/14.pdf. DOI: 10.30679/2219-5335-2019-5-59-155-166 (дата обращения: 31.01.2020).

6. Петров А.Н., Галстян А.Г. Актуальные аспекты противодействия фальсификации пищевых продуктов // Вопросы питания. 2016. № 5. С. 86-92.

7. Lapidus V.A., Kastorskaya L.V., Serov M.E., Voinova E.G. Principles and approaches to management in system of quality guarantee // Methods of Quality Management. 2018. № 7. P. 46-52.

8. AS 9145:2016. Requirements to Advanced Product Quality. Planning and Production Part Approval Process. [Электронный pecypc] URL: https://as9100store.com/wpcontent/uploads/2018/10/9145-2016_guidance-for-Aerospace.pdf (дата обращения: 01.12.2019).

9. Анисимов В.П., Яцук А.В. Метрология, стандартизация и сертификация (в сфере туризма). М.: Альфа-М, Инфра-М, 2017. 256 с.

10. Об утверждении критериев аккредитации, перечня документов, подтверждающих соответствие заявителя, аккредитованного лица критериям аккредитации, и перечня документов в области стандартизации, соблюдение требований которых заявителями, аккредитованными лицами обеспечивает их соответствие критериям аккредитации: Приказ Минэкономразвития России N 326 от 30 мая 2014 г. Доступ из справ.правовой системы «КонсультантПлюс».

11. ГОСТ ISO/IEC 17025-2019 Общие требования к компетентности испытательных и калибровочных лабораторий. М.: Стандартинформ, 2013. 33 с.

12. ГОСТ Р 51000.4-2011 Общие требования к аккредитации испытательных лабораторий. М.: Стандартинформ, 2013. 20 с.

13. ГОСТ Р ИСО 21748-2012 Статистические методы. Руководство по использованию оценок повторяемости, воспроизводимости и правильности при оценке неопределенности измерений. М.: Стандартинформ, 2014. 35 с. 
14. ГОСТ Р ИСО 5725-2002 Точность (правильность и прецизионность) методов и результатов измерений. Части 1-6. М.: Стандартинформ-2019, 36 с.

15. Magnusson B., Örnemark U. Eurachem Guide: The Fitness for Purpose of Analytical Methods - А [Электронный pecypc] Laboratory Guide to Method Validation and Related Topics. 2nd Edition. 2014. URL: https://www.eurachem.org (дата обращения: 01.12.2019).

16. Ellison S. L. R., Williams A. (eds). Eurachem/CITAC Guide: Quantifying Uncertainty in Analytical Measurement. 3rd Edition. 2012. [Электронный ресурc] URL: http://www.eurachem.org (дата обращения: 01.12.2019).

17. Milton M. Using the rules of natur to create the rules of measurement // Заводская лаборатория. Диагностика материалов. 2018. 84(4). С.71.

18. ISO 17034:2016. General requirements for the competence of reference material producers. [Электронный ресурс] URL: https://www.iso.org/standard 29357.html (дата обращения: 01.12.2019).

19. РМГ 61-2010. ГСОЕИ. Показатели точности, правильности, прецизионности методик количественного химического анализа. Методы оценки. М.: Стандартинформ, 2013. $59 \mathrm{c}$.

20. РМГ 76-2014. ГСОЕИ. Внутренний контроль качества результатов количественного химического анализа. М.: Стандартинформ, 2006. 116 с.

21. Третьяк Л.Н., Явкина Д.И. Внутренний контроль в обеспечении качества аналитических и испытательных лабораторий. Оренбург: ОГУ, 2018. 225 с.

22. Dvorkin E.I. Computerization of laboratories. Current state and metrological aspects. Industrial laboratory. Diagnostics of materials. 2018. 84(4). P. 73-77.

23. Упростить жизнь лаборатории призваны компьютерные программы [Электронный ресурс]. Компьютеризация лабораторных исследований. URL: https://www.qcontrol.ru (дата обращения: 01.12.2019).

24. ГОСТ Р ИСО 9001-2015 Системы менеджмента качества. Требования. М.: Стандартинформ, 2015. 25 с.

\section{References}

1. Hurshudyan S.A. Potrebitel' i kachestvo pishchevyh produktov // Pishchevaya promyshlennost'. 2014. № 5. S. 16-18.

2. Lapidus V.A., Kastorskaya L.V., Serov M.E., Voinova E.G. Principles and approaches to management in system of quality guarantee // Methods of Quality Management. 2018. № 7. P. 46-52.

3. Shelud'ko O.N., Strizhov N.K., Guguchkina T.I., Guzik T.V. Graficheskij obraz vysokokachestvennyh vin // Analitika i kontrol'. 2018. T. 22. № 3. S. 315-326.

4. Shelud'ko O.N., Strizhov N.K. Primenenie kompleksnogo analiza pri ocenke kachestva vinodel'cheskoj produkcii // Izvestiya vysshih uchebnyh zavedenij. Pishchevaya tekhnologiya. 2018. № 5-6 (365-366). S. 116-120.

5. Markovskij M.G., Burcev B.V., Guguchkina T.I., Shelud'ko O.N. Issledovanie raspredeleniya i vzaimosvyazi makro- i mikroelementov $\mathrm{v}$ vinah $\mathrm{v}$ celyah opredeleniya vozmozhnosti ih geograficheskoj identifikacii [Elektronnyj resurs] // Plodovodstvo i vinogradarstvo Yuga Rossii. 2019. № 59(5). S. 155-166. URL: http://journalkubansad.ru/pdf/19/05/14.pdf. DOI: 10.30679/2219-5335-2019-5-59-155-166 (data obrashcheniya: 31.01.2020).

6. Petrov A.N., Galstyan A.G. Aktual'nye aspekty protivodejstviya fal'sifikacii pishchevyh produktov // Voprosy pitaniya. 2016. № 5. S. 86-92.

7. Lapidus V.A., Kastorskaya L.V., Serov M.E., Voinova E.G. Principles and approaches to management in system of quality guarantee // Methods of Quality Management. 2018. № 7. P. 46-52. 
8. AS 9145:2016. Requirements to Advanced Product Quality. Planning and Production Part Approval Process. [Elektronnyj resurs] URL: https://as9100store.com/wpcontent/uploads/2018/10/9145-2016_guidance-for-Aerospace.pdf (data obrashcheniya: 01.12.2019).

9. Anisimov V.P., YAcuk A.V. Metrologiya, standartizaciya i sertifikaciya (v sfere turizma). M.: Al'fa-M, Infra-M, 2017. 256 c.

10. Ob utverzhdenii kriteriev akkreditacii, perechnya dokumentov, podtverzhdayushchih sootvetstvie zayavitelya, akkreditovannogo lica kriteriyam akkreditacii, i perechnya dokumentov v oblasti standartizacii, soblyudenie trebovanij kotoryh zayavitelyami, akkreditovannymi licami obespechivaet ih sootvetstvie kriteriyam akkreditacii: Prikaz Minekonomrazvitiya Rossii N 326 ot 30 maya 2014 g. Dostup iz sprav.-pravovoj sistemy «Konsul'tantPlyus»».

11. GOST ISO/IEC 17025-2019 Obshchie trebovaniya k kompetentnosti ispytatel'nyh i kalibrovochnyh laboratorij. M.: Standartinform, 2013. $33 \mathrm{~s}$.

12. GOST R 51000.4-2011 Obshchie trebovaniya k akkreditacii ispytatel'nyh laboratorij. M.: Standartinform, 2013. $20 \mathrm{~s}$.

13. GOST R ISO 21748-2012 Statisticheskie metody. Rukovodstvo po ispol'zovaniyu ocenok povtoryaemosti, vosproizvodimosti i pravil'nosti pri ocenke neopredelennosti izmerenij. M.: Standartinform, 2014. $35 \mathrm{~s}$.

14. GOST R ISO 5725-2002 Tochnost' (pravil'nost' i precizionnost') metodov i rezul'tatov izmerenij. CHasti 1-6. M.: Standartinform-2019, 36 s.

15. Magnusson B., Örnemark U. Eurachem Guide: The Fitness for Purpose of Analytical Methods - A [Elektronnyj resurs] Laboratory Guide to Method Validation and Related Topics. 2nd Edition. 2014. URL: https://www.eurachem.org (data obrashcheniya: 01.12.2019).

16. Ellison S. L. R., Williams A. (eds). Eurachem/CITAC Guide: Quantifying Uncertainty in Analytical Measurement. 3rd Edition. 2012. [Elektronnyj resurs] URL: http://www.eurachem.org (data obrashcheniya: 01.12.2019).

17. Milton M. Using the rules of natur to create the rules of measure-ment // Zavodskaya laboratoriya. Diagnostika materialov. 2018. 84(4). S.71.

18. ISO 17034:2016. General requirements for the competence of reference material producers. [Elektronnyj resurs] URL: https://www.iso.org/standard 29357.html (data obrashcheniya: 01.12.2019).

19. RMG 61-2010. GSOEI. Pokazateli tochnosti, pravil'nosti, precizionnosti metodik kolichestvennogo himicheskogo analiza. Metody ocenki. M.: Standartinform, 2013. $59 \mathrm{~s}$.

20. RMG 76-2014. GSOEI. Vnutrennij kontrol' kachestva rezul'tatov kolichestvennogo himicheskogo analiza. M.: Standartinform, 2006. $116 \mathrm{s.}$

21. Tret'yak L.N., YAvkina D.I. Vnutrennij kontrol' v obespechenii kachestva analiticheskih i ispytatel'nyh laboratorij. Orenburg: OGU, 2018. $225 \mathrm{s.}$

22. Dvorkin E.I. Computerization of laboratories. Current state and metrological aspects. Industrial laboratory. Diagnostics of materials. 2018. 84(4). R. 73-77.

23. Uprostit' zhizn' laboratorii prizvany komp'yuternye programmy [Elektronnyj resurs]. Komp'yuterizaciya laboratornyh issledovanij. URL: https://www.qcontrol.ru (data obrashcheniya: 01.12.2019).

24. GOST R ISO 9001-2015 Sistemy menedzhmenta kachestva. Trebovaniya. M.: Standartinform, 2015. $25 \mathrm{~s}$. 